Jurnal Teknologi, 54 (Sains \& Kej.) Keluaran Khas, Jan. 2011: 141-163

(C) Universiti Teknologi Malaysia

\title{
DATA-DRIVEN INDIRECT ADAPTIVE MODEL PREDICTIVE CONTROL
}

\author{
NORHALIZA WAHAB ${ }^{1 *}$, MOHAMED REZA KATEBI ${ }^{2}$, MOHD FUA'AD \\ RAHMAT $^{3} \&$ SALINDA BUNYAMIN $^{4}$
}

\begin{abstract}
This paper explores the design of Adaptive Model Predictive Control (AMPC) using Subspace State-space Model Identification (SMI) techniques for an activated sludge process. The implementation of SMI techniques in the adaptive sliding window control methods are discussed where the online subspace identification using Numerical State-space Subspace System Identification (N4SID) algorithm is proposed along with Model Predictive Control (MPC) design method. The online N4SID algorithm developed in this study makes use of the QR-updating where the combination of update and down date techniques enables sliding window adaptation. Here, at each time step, for the new experimental data added into $R$ factor, the oldest data are removed. Also, the Singular Value Decomposition (SVD-based) strategy is proposed into Indirect AMPC (IAMPC) for the control increment input constrained nonlinear system. Several simulation studies for different control parameters in control/identification algorithm are performed. For the IAMPC control design, the computational times involved using an SVD approach shows less burdensome compared to Quadratic Programming (QP) method and such an interesting result is considered as one of the main contribution in this paper.
\end{abstract}

Keywords: Adaptive control; activated sludge process; model predictive control; subspace identification

\begin{abstract}
Abstrak. Kertas kerja ini membincangkan tentang reka bentuk Pengawal Ramalan Model Suai menggunakan kaedah Pengenalpastian Model Keadaan Ruang Sub-ruang bagi proses enapcemar teraktif. Penggunaan teknik Pengenalpastian Model Keadaan Ruang Sub-ruang di dalam kaedah kawalan tingkat gelangsar suai dibincangkan di mana pengenalpastian sub-ruang dalam talian menggunakan algoritma N4SID di perkenalkan bersama dengan rekabentuk Pengawal ramalan model. Pembangunan N4SID dalam talian di dalam kertas kerja ini menggunakan pengemaskini QR di mana gabungan di antara teknik kemaskini dan kemasbawah membolehkan pengadaptasi tingkap gelangsar. Di sini, untuk setiap langkah masa, bagi setiap data baru akan dimasukkan ke
\end{abstract}

\footnotetext{
Faculty of Electrical Engineering, University Teknologi Malaysia, 81310 UTM Johor Bahru, Johor Darul Taazim, Malaysia

Industrial Control Centre, Dept of Electronic and Electrical Engineering, University of Strathclyde, Glasgow, US

Corresponding author : aliza@fke.utm.my
} 
faktor $R$ manakala data yang lama dibuang. Begitu juga, strategi bagi uraian nilai tunggal diperkenalkan ke dalam Pengawal Ramalan Model Suai tak langsung untuk masukan tambahan kawalan bagi sistem terkekang tak lelurus. Beberapa kajian simulasi bagi parameter kawalan berlainan di dalam pengawal/pengenalpastian algoritma dilaksanakan. Bagi reka bentuk Pengawal Ramalan Model Suai tak langsung, pengiraan masa yang terlibat dengan menggunakan pendekatan uraian nilai tunggal kurang berbanding dengan kaedah perancangan kuadratik dan keputusan yang memberangsangkan ini adalah sumbangan utama di dalam kertas kerja ini.

Kata kunci: Pengawal suai; proses enapcemar teraktif; pengawal ramalan model; pengenalpastian sub-ruang

\subsection{INTRODUCTION}

Often, polynomial transfer function is employed in the derivation of adaptive control method [1]. This paper studies the use of subspace model identification techniques to develop a state-space based adaptive control technique for model predictive control design. Using these techniques, state-space matrices can be constructed and used to obtain prediction of the process outputs. These predictions can subsequently serve as a basis for Model Predictive Control (MPC) controller design. By continuously updating these models, an adaptive model predictive control method can be obtained.

MPC also referred to as sliding (receding) horizon control has become standard approach in advanced process control. The main idea of MPC is to choose the control action by repeatedly solving online an optimal control problem. This aims at minimising a performance criterion over a future horizon, where the future behavior is computed according to a model of the plant. Moreover, the ability of MPC algorithm to deal with constrained multivariable system directly is well known. There are probably some issues arise from MPC algorithm such as closed loop stability, model uncertainty and online computations. Since all the computation in adaptive control MPC has to be carried out at every sampling time, more computation is required and this is even higher when the constraints are included. The adaptive MPC optimisation is to be solved online either by using Quadratic Programming (QP), Linear Programming (LP) or Nonlinear Programming (NLP). For a finite horizon optimal control problem, the quadratic cost can be cast into a numerically efficient QP algorithm $[2,3,4]$.

However, large scale problems with a large number of variables and/or those with long horizons, LPs and QPs require a high computational load. Often, NLP is solved by sequential quadratic programming (SQP) which is computationally very expensive. This type of optimization also gives no guarantee of convergence to a global minimum. Many efforts have recently been devoted to reduce the 
online computational burden regarding to QP solver. A finitely parameterized method that gives explicit solution to QP problems can be found in [5] and [6]. The offline computation for the explicit QP solution is of great advantage in this method. However, as the prediction horizon increases, the more complex the state partition to be handled becomes. Another approach to reduce the online computation is to implement the suboptimal solution of QP problem [7, 8]. Another way to increase the efficiency and reliability of the solution is to exploit the structure of the problem, i.e. the performance index. The exploitation of a highly structured Hessian and the constraint matrices of the QPs has been shown to speed up the computation by an order of the magnitude [9]. Another suboptimal approach is to implement receding horizon control strategy, based on a Singular Value Decomposition (SVD) of the Hessian of the quadratic performance index generally used in MPC [10].

The main purpose of this paper is to study the use of SMI technique to find state-space representation of a model to implement indirect adaptive MPC controllers for a biological wastewater treatment system. Other works on adaptive control for activated sludge process are [11, 12, 13]. In a previous work of Dochain [11], a set of reduced order model of the plant is obtained by singular pertubation of the state space model of the activated sludge process. The idea presented here is to use data-driven control models to develop IAMPC control. Conventional MPC uses QP algorithm to minimise a certain cost function over $N$ linearly constrained control inputs. In this paper, an improved performance can then be expected by exploiting the singular value decomposition structure in the constrained multivariable IAMPC.

The paper is organized as follows. Section 2 describes the subspace model identification in an adaptive framework. Here, the N4SID algorithm is implemented and the updated data Hankel matrix is presented. A brief overview of the formulation and solution of the IAMPC control is presented in Section 3. In this section, the sliding window adaptive method is presented and applied to the constrained multivariable system. The proposed SVD-based strategy of the optimization problem is also given in this section. In Section 4, the activated sludge process is described. Section 5 presents the simulation results where the effects of different design parameters are studied. Finally, conclusions are drawn in Section 6 .

\subsection{SUBSPACE IDENTIFICATION IMPLEMENTED IN ADAPTIVE CONTROL}

Consider a linear discrete time invariant state-space system in the form: 


$$
\begin{aligned}
& x(k+1)=A x(k)+B \Delta u(k)+K v(k) \\
& y(k)=C x(k)+D \Delta u(k)+v(k)
\end{aligned}
$$

where $u(k), y(k)$ and $x(k)$ are the inputs, outputs and states respectively and $v(k)$ is a white noise sequence with zero-mean and variance $E\left[e_{p} e_{q}^{T}\right]=S \delta_{p q} . A, B, C, D$, and $K$ are system matrices with appropriate dimensions. We assume that $\left\{\begin{array}{ll}A & B\end{array}\right\}$ is controllable and $\left\{\begin{array}{lll}A & C\end{array}\right\}$ is observable. The following matrix input-output equations [14] play an important role in the problem treated in linear subspace identification and it can be obtained by recursive substitution of Eqs. (3)-(4):

$$
\begin{aligned}
& Y_{f}=\Gamma_{i} X_{f}+H_{i} U_{f} \\
& Y_{p}=\Gamma_{i} X_{p}+H_{i} U_{p}
\end{aligned}
$$

where the data block Hankel matrices for $u(k)$ represented as $U_{p}$ and $U_{f}$ and defined as:

$$
\begin{aligned}
& U_{p}=\left(\begin{array}{cccc}
u_{0} & u_{1} & \cdots & u_{j-1} \\
u_{1} & u_{2} & \cdots & u_{j} \\
\vdots & \vdots & \ddots & \vdots \\
u_{i-1} & u_{i} & \cdots & u_{i+j-2}
\end{array}\right) \\
& U_{f}=\left(\begin{array}{cccc}
u_{i} & u_{i+1} & \cdots & u_{i+j-1} \\
u_{i+1} & u_{i+2} & \cdots & u_{i+j} \\
\vdots & \vdots & \ddots & \vdots \\
u_{2 i-1} & u_{2 i} & \cdots & u_{2 i+j-2}
\end{array}\right)
\end{aligned}
$$

where the subscripts $p$ and $f$ represent 'past' and 'future' time. The same way, the outputs block Hankel matrices $Y_{p}$ and $Y_{f}$ can be defined. $i$ is the prediction $\left(i=H_{p}\right)$ and $j$ is receding window size, $n$ respectively. The extended observability matrix, $\Gamma_{i}$ and the lower block triangular Toeplitz matrix, $H_{i}$ are defined as:

$$
\Gamma_{i}=\left(\begin{array}{c}
C \\
C A \\
\vdots \\
C A^{i}
\end{array}\right), H=\left(\begin{array}{cccc}
C B & 0 & \cdots & 0 \\
C A B & C B & \cdots & 0 \\
\vdots & \vdots & \ddots & \vdots \\
C A^{i-1} B & C A^{i-2} B & \cdots & C B
\end{array}\right)
$$


The basic idea of subspace identification method is that, from the previously defined matrix input-output equations in Eqs. (3)-(4), it can be observed that the block data Hankel matrix containing the future outputs $Y_{f}$ which is linearly related to the future state sequences $X_{f}$ and the future inputs $U_{f}$. Therefore, the main framework of subspace model identification is to recover the $\Gamma_{i} X_{f}$ term, whereby from the knowledge of either $\Gamma_{i}$ or $X_{f}$, the state space model can be retrieved in a least square sense [15].

\subsection{Online N4SID Implementation}

If subspace model identification algorithms are to be implemented with adaptive control, model parameters are required to be updated online, it is then necessary to develop an efficient technique in order to update the matrix estimates. Therefore, it involves updating an input-output Hankel matrices for a given new sample. To allow for a rapid additional or removal of new input-output data, a combination of updating and downdating the QR decomposition is performed making use of the rank-one modification [16]. The QR decomposition is given as follows:

$$
\left(\begin{array}{c}
U_{f} \\
W_{p} \\
Y_{f}
\end{array}\right)=\left(\begin{array}{ccc}
R_{11} & 0 & 0 \\
R_{21} & R_{22} & 0 \\
R_{31} & R_{32} & R_{33}
\end{array}\right)\left(\begin{array}{c}
Q_{1}^{T} \\
Q_{2}^{T} \\
Q_{3}^{T}
\end{array}\right)
$$

Assume that, at time $k+1$, new set of input-output data vectors are acquired and hence, each of the block Hankel matrices is modified by addition of a column vector input, $u$ :

$$
\begin{aligned}
& u_{p}(k+1)=\left(\begin{array}{lll}
u_{j} & \ldots & u_{i+j-1}
\end{array}\right)^{T} \\
& u_{f}(k+1)=\left(\begin{array}{lll}
u_{i+j} & \ldots & u_{2 i+j-1}
\end{array}\right)^{T}
\end{aligned}
$$

A similar notation can be defined for the addition of a column vector output, $y$. By using rank-one update to $\mathrm{QR}$ factorization, the elements of a new column vector are added, i.e.: 


$$
\left(\begin{array}{cc}
U_{f} & u_{f}(k+1) \\
W_{p} & w_{p}(k+1) \\
Y_{f} & y_{f}(k+1)
\end{array}\right)=\left(\begin{array}{cccc}
R_{11}(k) & 0 & 0 & u_{f}(k+1) \\
R_{21}(k) & R_{22}(k) & 0 & w_{p}(k+1) \\
R_{31}(k) & R_{32}(k) & R_{33}(k) & y_{f}(k+1)
\end{array}\right)\left(\begin{array}{cc}
Q_{1}{ }^{T} & 0 \\
Q_{2}{ }^{T} & 0 \\
Q_{3}{ }^{T} & 0 \\
0 & 1
\end{array}\right)
$$

A series of rotations can be used to zero out the appropriate elements of the factorization. The elements of a new column vector are zeroed by first applying it to $u_{f}(k+1)$ :

$$
\left(\begin{array}{cccc}
R_{11}(k+1) & 0 & 0 & 0 \\
R_{21}(k+1) & R_{22}(k+1) & 0 & 0 \\
R_{31}(k+1) & R_{32}(k+1) & R_{33}(k) & \overline{\bar{\varepsilon}}_{f}(k+1)
\end{array}\right)
$$

The updating procedure for $R(k+1)$ in Eqs. (10) and (11) is:

$R(k+1)=R(k)+\bar{\varepsilon}_{f}(k+1) \bar{\varepsilon}_{f}(k+1)^{T}-\overline{\bar{\varepsilon}}_{f}(k+1) \overline{\bar{\varepsilon}}_{f}(k+1)^{T}$

Basically, the calculation of an SVD is given as:

$$
S=\left(\begin{array}{ll}
U_{1} & U_{2}
\end{array}\right)\left(\begin{array}{cc}
\Sigma_{1} & 0 \\
0 & 0
\end{array}\right)\left(\begin{array}{c}
V_{1}^{T} \\
V_{2}^{T}
\end{array}\right)
$$

where $U$ is the left singular vector, $\Sigma_{1}$ has singular values and is diagonal and $V^{T}$ is the right singular vector. The extraction of $\Gamma_{\mathrm{i}}$ and $X_{f}$ can be carried out in a very simple way by means of a SVD of the matrix $\hat{E}_{\| U_{f}}\left\{Y_{f} \mid W_{p}\right\}$.

The estimation of the system matrices can be obtained by solving the linear equations:

$$
\left(\begin{array}{c}
X(k+1) \\
Y(k)
\end{array}\right)=\left(\begin{array}{ll}
A & B \\
C & D
\end{array}\right)\left(\begin{array}{l}
X(k) \\
U(k)
\end{array}\right)
$$

Thus,

$$
\left(\begin{array}{cc}
\hat{A} & \hat{B} \\
\hat{C} & \hat{D}
\end{array}\right)=\left(\left[\begin{array}{c}
X(k+1) \\
Y(k)
\end{array}\right]\left[\begin{array}{l}
X(k) \\
U(k)
\end{array}\right]^{T}\right)\left(\left[\begin{array}{c}
X(k) \\
U(k)
\end{array}\right]\left[\begin{array}{l}
X(k) \\
U(k)
\end{array}\right]^{T}\right)^{-1}
$$

Using the rank-one modification, a combination of update and downdate techniques enables sliding window adaptation, whereby at each time step, the new 
data are added to matrix $R$ and the oldest data are removed. The system matrices are therefore computed from $R$ using the SVD. As seen in the above derivation, the basic concept of subspace model identification is similar, differs only in this case by the algorithm is to be implemented online. The following is a summary of the algorithm.

Algorithm 2.1 Online subspace model identification

Step 1: Construct data block Hankel matrix, i.e. $U_{f}, U_{p}, Y_{p}, Y_{f}$ from a given inputoutput data.

Step 2: Compute $\hat{E}_{\| U_{f}}\left\{Y_{f} \mid W_{p}\right\}$ and the QR decomposition of Eq. (8).

Step 3: Calculate the SVD of the matrix $\hat{E}_{\| U_{f}}\left\{Y_{f} \mid W_{p}\right\}$

Step 4: Compute the matrices $A, B, C, D$ by solving the least square problem in Eq. (16).

Step 5: Update the Hankel matrix through adding the input-output data and removing the oldest ones. Go to step 2 and repeat.

\subsection{INDIREGT ADAPTIVE MPG}

The indirect adaptive control implemented in this work uses data-driven approach where the controller parameters are identified using input-output data. The inputs of the open loop identification data are white and zero-mean and often used as inputs for system identification. The classical two-step of controller design is performed. First is the estimation of state sequences and/or extended observability matrix. In the open-loop subspace state-space identification, the extended observability matrix, $\Gamma_{i}$ and the state sequence of Kalman filter, $X_{f}$ can be obtained using the singular value decomposition of the matrix, $Y_{f} / U_{f} W_{p}$.

Later, the state space matrices $A, B, C, D$ can be estimated by using either the extended observability matrix, $\Gamma_{i}$ or/and the Kalman filter estimate, $X_{f}$ (such as N4SID). The system matrix estimated provided by the N4SID algorithm is then used to set up the prediction matrices. A possible structure of an adaptive control using the online N4SID algorithm along with MPC control design is shown in Fig.1. 


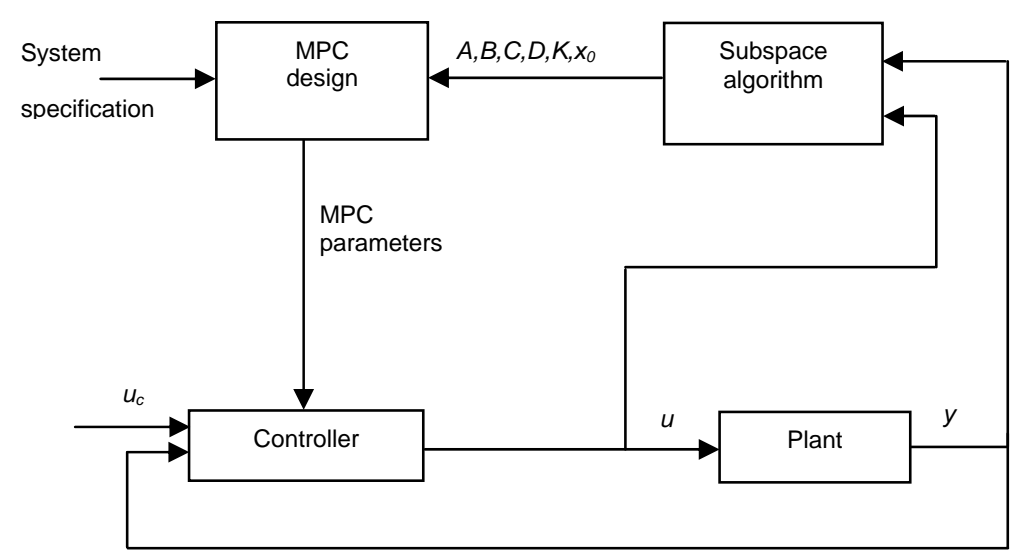

Figure 1 Indirect adaptive control using MPC

\subsection{Sliding Window}

In this IAMPC control design, the measured data is collected over a sliding window. The procedure of using a sliding window for identification is illustrated in Fig. 2. It can be noted that the data window used to identify state space matrices can be expressed in term of future input $u_{f}=\left(\begin{array}{lll}u_{i-1} & \ldots & u_{2 i-2}\end{array}\right)^{T}$ and measurement (past) inputs, $u_{p}=\left(\begin{array}{llll}u_{0} & \ldots & u_{i-1}\end{array}\right)^{T}$ and outputs, $y_{p}=\left(\begin{array}{lll}y_{0} & \ldots & y_{i-1}\end{array}\right)^{T}$. Here, two prediction problems given at current time instant $i$ and $i+1$ are shown Fig. 2. The first prediction problem $(t=i)$ represents the case for obtaining the optimal prediction of $i$ future outputs $\hat{y}_{f}=\left(\begin{array}{lll}\hat{y}_{i} & \ldots & \hat{y}_{2 i-1}\end{array}\right)^{T}$ using the information given in the previously stated data window $u_{p}, y_{p}$ and $u_{f}$. The second prediction problem shows that the time instant slides (i.e. $t=i$ to $t=i+1$ ), this differs from the data window $\left(u_{p}, y_{p}\right.$ and $\left.u_{f}\right)$ which is now slides from left to right. At every time step, for the new available input-output data, the state space parameters are updated online and the new control action is computed. The main advantage of this approach is that the controller parameters are updated at each sample, which usually means a quicker response to process changes via a combination of updating and downdating steps. The main drawback of this method is that an QR decomposition needs to be computed at each sample instance, which increases the computational load. 


\subsection{CONSTRAINED IAMPC CONTROL}

The implemented MPC control design allows the solution of control problem with constraints on $\Delta \mathrm{u}$. In the constraint case, the computational burden is an important issue to be considered. In this study, the constrained optimal solution to the minimisation of quadratic performance index has been solved online using a standard quadratic programming which requires heavy computational load. This becomes increasingly more difficult as the prediction horizon increases and hence large receding window size is used. The online computational burden is linearly proportional to the size of the window. To reduce the online computational load associated with the solution of QP, an SVD-based strategy is proposed here. In this case, the structure of the performance index is analysed based on SVD approach in a context of subspace adaptive frameworks.

By iterating the model in Eq. (1) - (2), the prediction output is defined as:

$$
\hat{y}_{f}=\Gamma x+H \Delta u
$$

The quadratic performance index can be expressed as follows:

$$
J=e^{T} Q e-2 \Delta u^{T} H^{T} Q e+\Delta u^{T} \mho \Delta u
$$

where $\mho=H^{T} Q H+R \in \mathbb{R}^{H_{c} N_{u} \times H_{c} N_{u}}$ and $e=r_{f}-\Gamma x$. The IAMPC control law can be found by making the gradient of $J$ zero, therefore:

$$
\Delta u=\mho^{-1} H^{T} Q e
$$

By using SVD-based strategy, the performance index, $J$ can now be rewritten as:

$$
J=e^{T} Q e-2 \Delta \tilde{u}^{T} V^{T} H^{T} Q e+\Delta \tilde{u}^{T} \Sigma \Delta \tilde{u}
$$

Thus, the unconstrained optimal $\Delta u$ is:

$$
\Delta \tilde{\mathrm{u}}_{u c}=\Sigma^{-1} V^{T} H^{T} Q e
$$




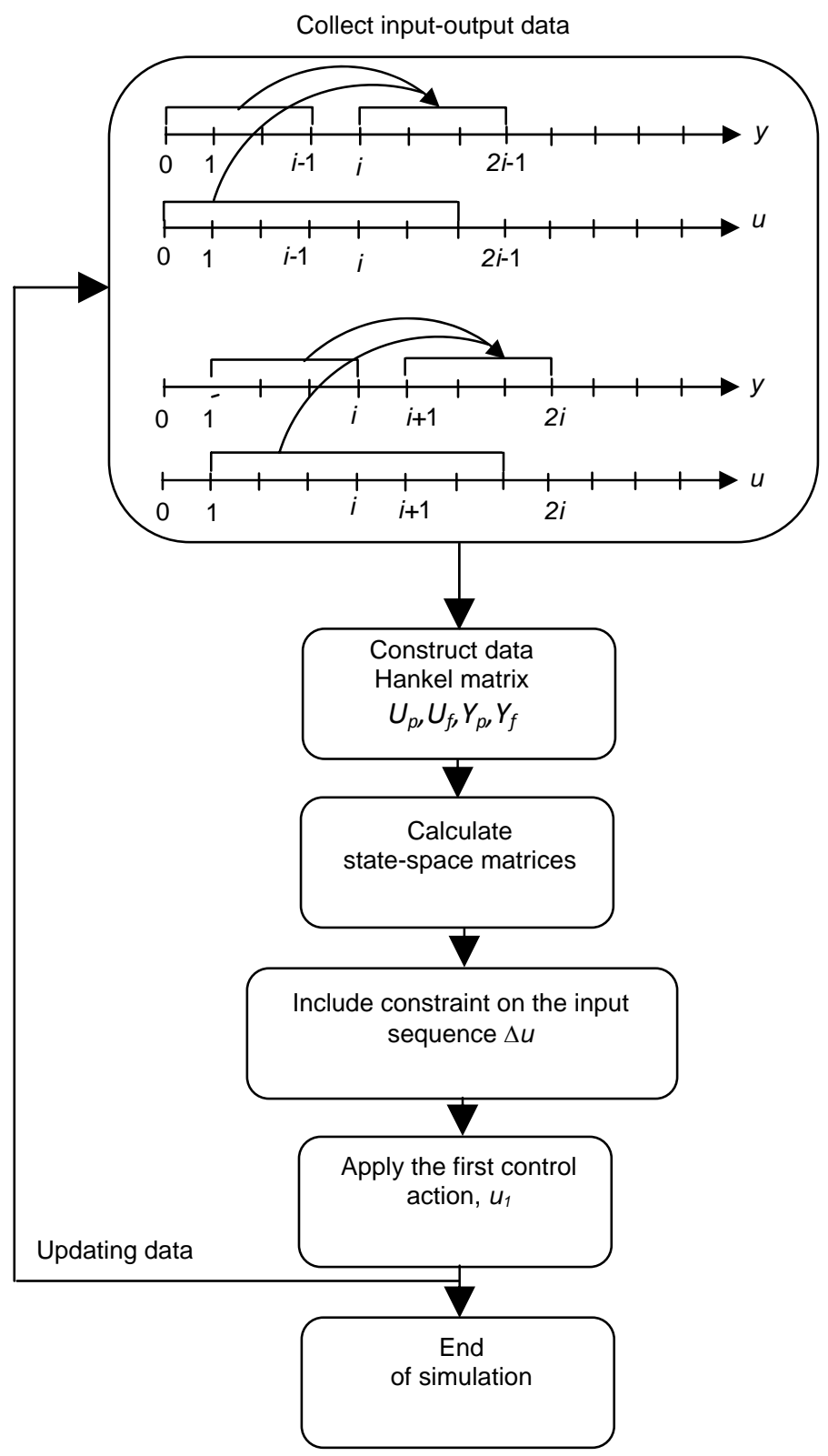

Figure 2 Sliding window for $i=4$ 
The increment input vectors for the constrained case can be constructed by considering the modification of the unconstrained solution, $\Delta \tilde{u}_{u c}$ in Eq. (21). Let us first define the performance index, $J$ as:

$$
\min _{\Delta u} J=J_{u c}+\sum_{i=1}^{H_{c} N_{u}} \sigma_{i}\left(\Delta \tilde{u}_{i}-\Delta \tilde{u}_{u c, i}\right)^{2}
$$

where $\Delta \tilde{u}_{u c, i}$ is the $i^{\text {th }}$ entry of vector $\Delta \tilde{u}_{u c}$. From Eq. (22), it can be observed that whenever $\Delta \tilde{u}_{i}=\Delta \tilde{u}_{u c, i}$, we obtain $J=J_{u c}$, which is the unconstrained value. Note that the entries of $\Delta u$ in Eq. (22) are arranged in decreasing order of magnitude, since $\sigma_{1} \geq \sigma_{2} \geq \ldots \geq \sigma_{H_{c} N_{u}} \geq 0$, which starting from the one that influences the performance index the most and ending with the one that influences the performance index the least.

Therefore, to find a feasible solution to the constrained optimisation problem $J$, we need to consider the components in the entries of vector $\Delta \tilde{u}_{u c}$ with highest contribution in reducing the magnitude of $J$, i.e. use those elements of $\Delta \tilde{u}_{u c}$ with the biggest singular values. $\Delta \tilde{u}_{u c}$ for the unconstrained solution is:

$$
\Delta u_{u c}=V \Delta \tilde{u}_{u c}=\sum_{i=1}^{H_{c} N_{u}} v_{i} \Delta \tilde{u}_{u c, i}
$$

The vector $\Delta \tilde{u}_{u c}$ in Eq. (21) will be ordered from the highest to the smallest singular values and progressively discarding smaller components, until the constraints are satisfied, i.e.:

$$
\Delta u_{u c}=V\left(\begin{array}{lllllll}
\Delta \tilde{u}_{1, u c} & \ldots & \Delta \tilde{u}_{m, u c} & 0 & \ldots & 0
\end{array}\right)^{T}
$$

where $m \in I_{H_{c} N_{u}} \triangleq\left\{\begin{array}{lll}1 & \ldots & H_{c} N_{u}\end{array}\right\}$. This does not necessarily gives the best control performance, hence the following control increment vector is defined:

$$
\Delta u_{s v d}=\sum_{i=1}^{m} v_{i} \Delta \tilde{u}_{i, u c}+\left(v_{m+1} \alpha \Delta \tilde{u}_{m+1, u c}\right)
$$

where $0 \leq \alpha \leq 1$ and $m \in I_{H_{c} N_{u}} \triangleq\left\{\begin{array}{lll}1 & \ldots & H_{c} N_{u}\end{array}\right\}$. To obtain the best solution $\alpha$ should be as large as possible while the constraints are satisfied. For $m=H_{c} N_{u}$, $\alpha=0$ and the solution is unconstrained. The IAMPC algorithm is summarised here. 


\section{Algorithm 3.2: IAMPC Control Method}

Step 1: Construct data block Hankel matrix, i.e. $U_{f}, U_{p}, Y_{p}, Y_{f}$ from a given inputoutput data.

Step 2: Compute the matrices $A, B, C, D$ by solving the least square problem.

Step 3: Compute the optimal unconstrained solution $\Delta \tilde{u}_{u c}=\Sigma^{-1} V^{T} H^{T} Q e$

Step 4: Find the "largest" $\theta=m+\alpha$, where $0 \leq \alpha \leq 1$ such that the vector:

$$
\Delta u_{s v d}=V \Delta \tilde{u}_{s v d}=V\left(\begin{array}{llllllll}
\Delta \tilde{u}_{1, u c} & \ldots & \Delta \tilde{u}_{m, u c} & \alpha \Delta \tilde{u}_{m+1, u c} & 0 & \ldots & 0
\end{array}\right)^{T}
$$

lies on the boundary of the constraint set in $\mathbb{R}^{H_{c} N_{u}}$ and $\Delta u_{\text {svd }} \in \Delta \mathbb{R}$. The parameters $m$ and $\alpha$ are tuned for the best performance whilst the constraints are satisfied Step 5: At time $k$, only $\Delta u_{\text {svd }}(1)$ is implemented and the calculation is repeated at each time instant, i.e. $u(k)$ is implemented as: $u(k)=u(k-1)+\Delta u(k)$

Step 6: Update the Hankel matrix using the newest data and go to step 2 and repeat.

\subsection{ACTIVATED SLUDGE PROCESS}

The activated sludge process in wastewater treatment plant is comprised of an aerator and a settler as shown in Fig.3.

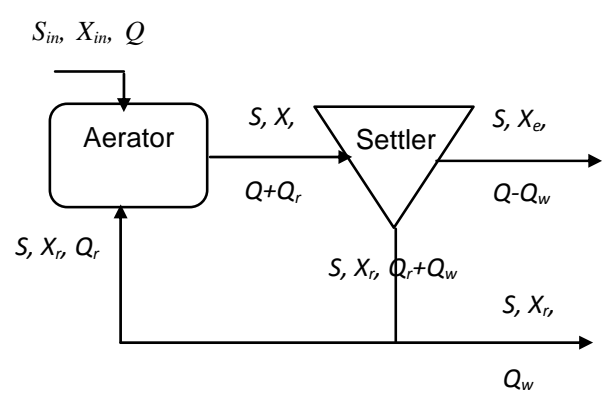

Figure 3 Activated sludge process

The bioreactor includes a secondary clarifier that serves to retain the biomass in the system while producing a high quality effluent. Part of the settled biomass is recycled to allow the right concentration of micro-organisms in the aerated tank. A component mass balance that yields the following set of nonlinear differential equations was previously derived in [17]. 


$$
\begin{gathered}
\dot{X}(t)=\mu(t) X(t)-D(t)(1+r) X(t)+r D(t) X_{r}(t) \\
\dot{S}(t)=-\frac{\mu(t)}{Y} X(t)-D(t)(1+r) S(t)+D(t) S_{i n} \\
C(t)=\frac{K_{o} \mu(t) X(t)}{Y}-D(t)(1+r) C(t)+K_{L a}\left(C_{s}-C(t)+D(t) C_{i n}\right) \\
\dot{X}_{r}(t)=D(t) \cdot(1+r) \cdot X(t)-D(t) \cdot(\beta+r) X_{r}(t)
\end{gathered}
$$

where the state variables, $X(t), S(t), C(t)$ and $X_{r}(t)$ represent the concentrations of biomass, substrate, dissolved oxygen (DO) and recycled biomass respectively. $D(t)$ is the dilution rate, while $S_{i n}$ and $C_{i n}$ correspond to the substrate and DO concentrations of influent stream. The parameters $r$ and $b$ represents the ratio of recycled and waste flow to the influent flow rate, respectively. The kinetics of the cell mass production is defined in terms of the specific growth rate $\mu$ and the yield of cell mass $Y$. The term $K_{o}$ is a constant. $C_{s}$ and $K_{L a}$ denote the maximum dissolved oxygen concentration and the oxygen mass transfer coefficient, respectively. The Monod equation gives the growth rate related to the maximum growth rate, to the substrate concentration, and to DO concentration:

$$
\mu(t)=\mu_{\max } \frac{S(t)}{K_{s}+S(t)} \frac{C(t)}{K_{c}+C(t)}
$$

where $\mu_{\max }$ is the maximum specific growth rate, $K_{s}$ is the affinity constant and $K_{c}$ is the saturation constant. In this simulation, two controlled outputs substrate (S) and DO and two manipulated inputs dilution rate (D) and airflow rate (W) are considered.

\subsection{EVALUATION AND SIMULATION RESULTS}

Simulations were carried out for the IAMPC control design method based on the singular value of the optimisation problem applied to the activated sludge wastewater treatment process. The aim of the control is to keep the pollutant substrate concentration and the dissolved oxygen concentration level to a given setpoints as the disturbances pertubes the system. In this control design method, the design parameters are chosen both for identification and control stages. In the identification stage, the identification window size, $n$ and sampling interval, $T_{s}$ were selected. In addition to that, various parameters needed to be chosen in the control design parameters such as sampling interval, $T_{s}$, prediction horizon, $H_{p}$, control horizon, $H_{c}$, the input and output weighting matrices $R$ and $Q$ as well as the constraint limit on control input increments, $\Delta u$. Some parameters considered 
here are varied to demonstrate its effect on the performance as well as the computational time involved. The performance of SVD-based IAMPC is compared to QP-based IAMPC with respect to computational complexity.

The following sections present several model analyses and demonstrate the effect of parameters changes, such as $H_{p}$ and $n$ due to the excitation of input disturbance in the system at $t=1285$. The simulation is run from a steady state operating point at outputs $S=41.23 \mathrm{mg} / \mathrm{l}, \mathrm{DO}=6.11 \mathrm{mg} / \mathrm{l}$ and inputs $D=0.08 \mathrm{1} / \mathrm{h}$ and $W=90 \mathrm{~m}^{3} / \mathrm{hr}$. The sampling interval is chosen as $T \mathrm{~s}=1$. The output weighting, $Q$ and input weighting, $R$ are respectively given as $Q=\operatorname{diag}(1 ; 10)$ and $R=$ $\operatorname{diag}\left(10^{4} ; 10^{-4}\right)$.

\subsection{Model Analysis}

The behaviour of the singular values of the Hessian, $\mho$ for different prediction horizons, $H_{p}$ is studied and is shown in Fig. 4. Fig. 4 shows that the longer prediction horizon $H_{p}$ leads to a common issue of ill-conditioning of matrix, $\mho$. Clearly, large singular values can be observed when $H_{p}$ is increased, which indicates large gain between the corresponding control basis vector and the cost function.
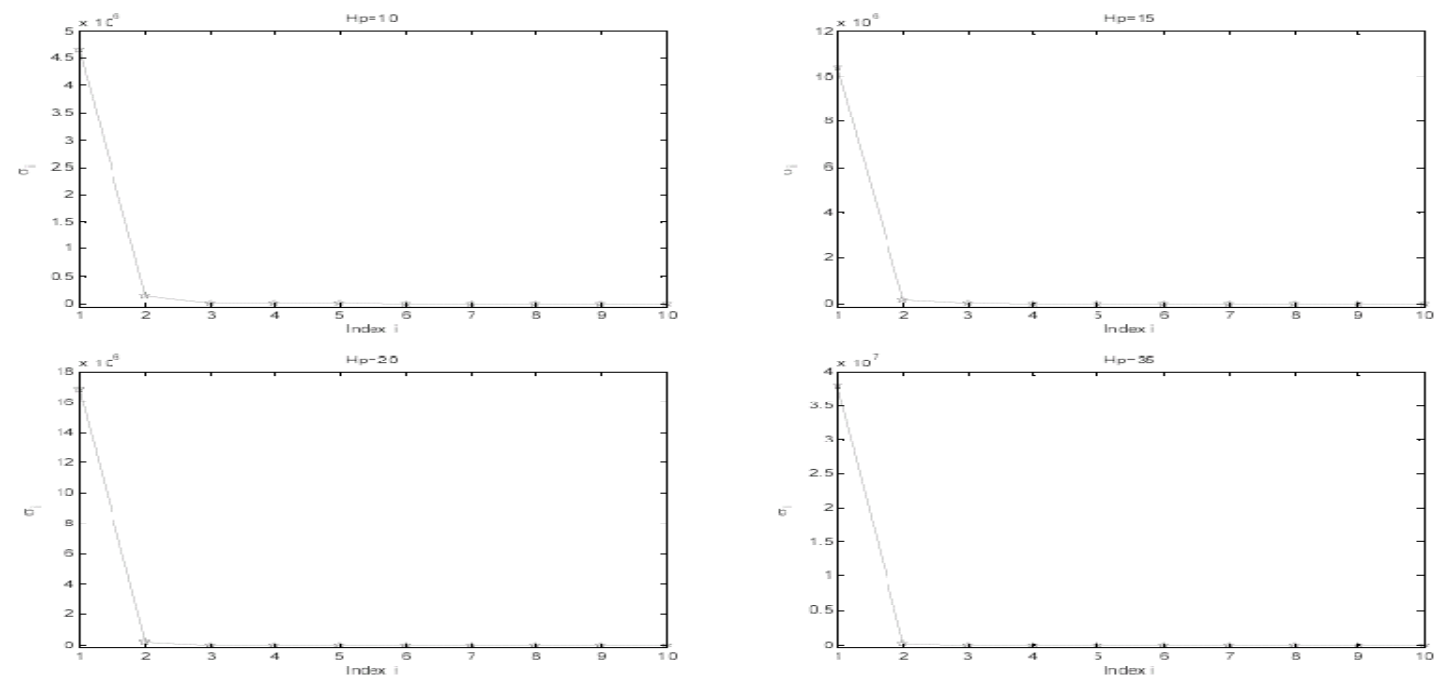

Figure 4 Singular value of Hessian matrix for different $H_{p}$ 


\subsection{Effect Of $n$}

Three different sizes of the identification window, $n$ are demonstrated $(n=200 ; n$ $=400 ; n=900)$. The prediction horizon is set to $H_{p}=20$ for all given $n$. Therefore, for a constant prediction horizon, each test case uses a slightly different number of input-output data. The control horizon is set to $H_{c}=5$. Figures (5-6) show that the closed loop performance behaves differently for different $n$ when the system is excited with input pertubation at $t=1285$. The controller converges quickly at $n=200$, though more oscillations are present in response to disturbance. As the data window size is increased, i.e. $n=900$ which leads to more data available for control design, less oscillations are present. However, the controller takes longer to converge. The trade-off between the selection of the identification window size, $n$ and diturbance rejection performance is therefore considered when applied to a nonlinear activated sludge process. 

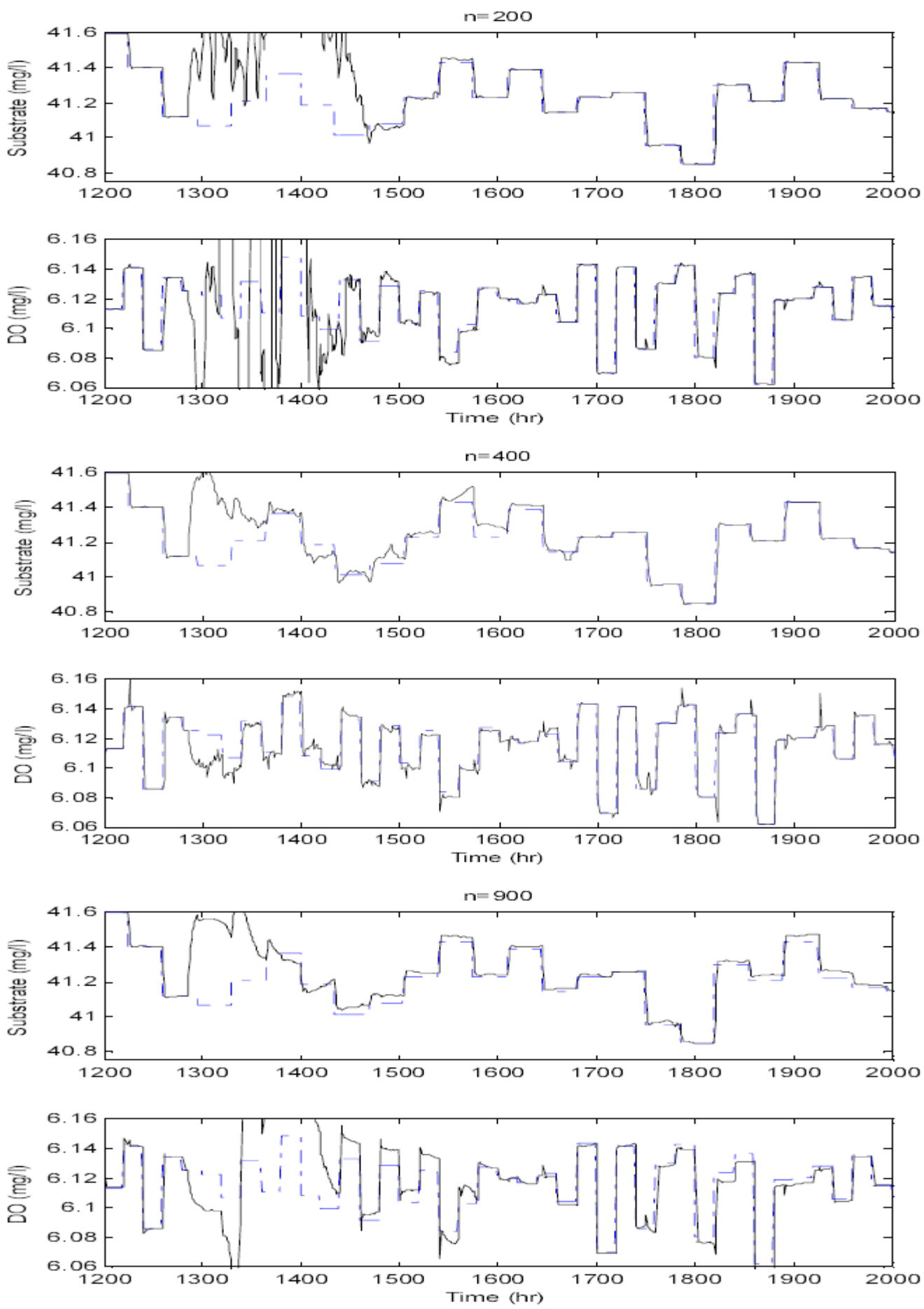

Figure 5 Performance comparison for different $n$-output response 

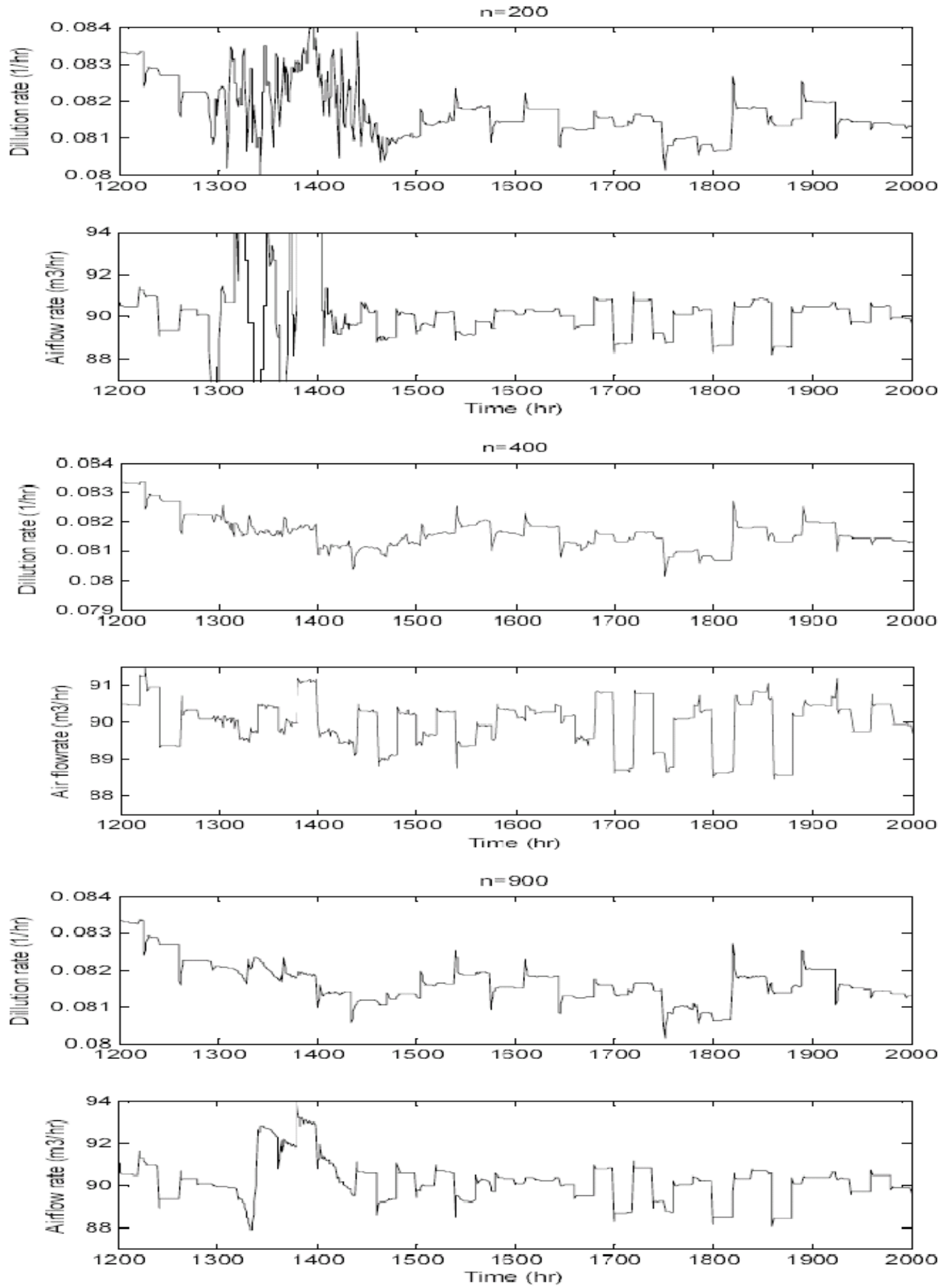

Figure 6 Performance comparison for different $n$-input response 


\section{$5.3 \quad$ EFFECT OF $H p$}

In this section, different prediction horizons are given and its effect on the control performance are studied. The choice of $H_{p}$ is primarily a trade-off between the order of the controller and the control performance. Fig. 7 and Fig. 8 show the output and input responses, respectively with varying $H_{p}$ with the identification window fixed at $n=400$.

As seen in Figures (7-8), for a given input disturbance at $t=1285$, the responses react differently as the prediction horizon decreases. Four different prediction horizons are tested given as $H_{p}=35,20,15$, and 10. Improved performance is demonstrated starting from $H_{p}=20$ as shown in Fig. 7. This can be observed clearly that is, the responses stabilise well and able to track back to setpoint faster. The controller converges quickly at $H_{p}=20$ (at around $t=1700$ ). As prediction horizon is increased, i.e. $H_{p}=35$ it shows some oscillatory response due to disturbance acting on the system. For $H_{p}=35$, the output responses (both for DO and Substrate) exhibit worst tracking properties and takes longer to settle. The general trend is, as the prediction horizon, $H_{p}$ is increases, $n$ should be increased, so that $\left(\mathrm{j}>\mathrm{i}\right.$ ). Note that, for $n=400$, each of the test cases (where different $H_{p}$ is applied), $j=n 2 H_{p}+1$ gives a slightly different $j$ prediction problem. In general, longer prediction horizon leads to better closed loop performance. In this case, the use of larger $n$ is therefore needed for $H_{p}=35$, for better setpoint tracking as well as good disturbance rejection performance. 

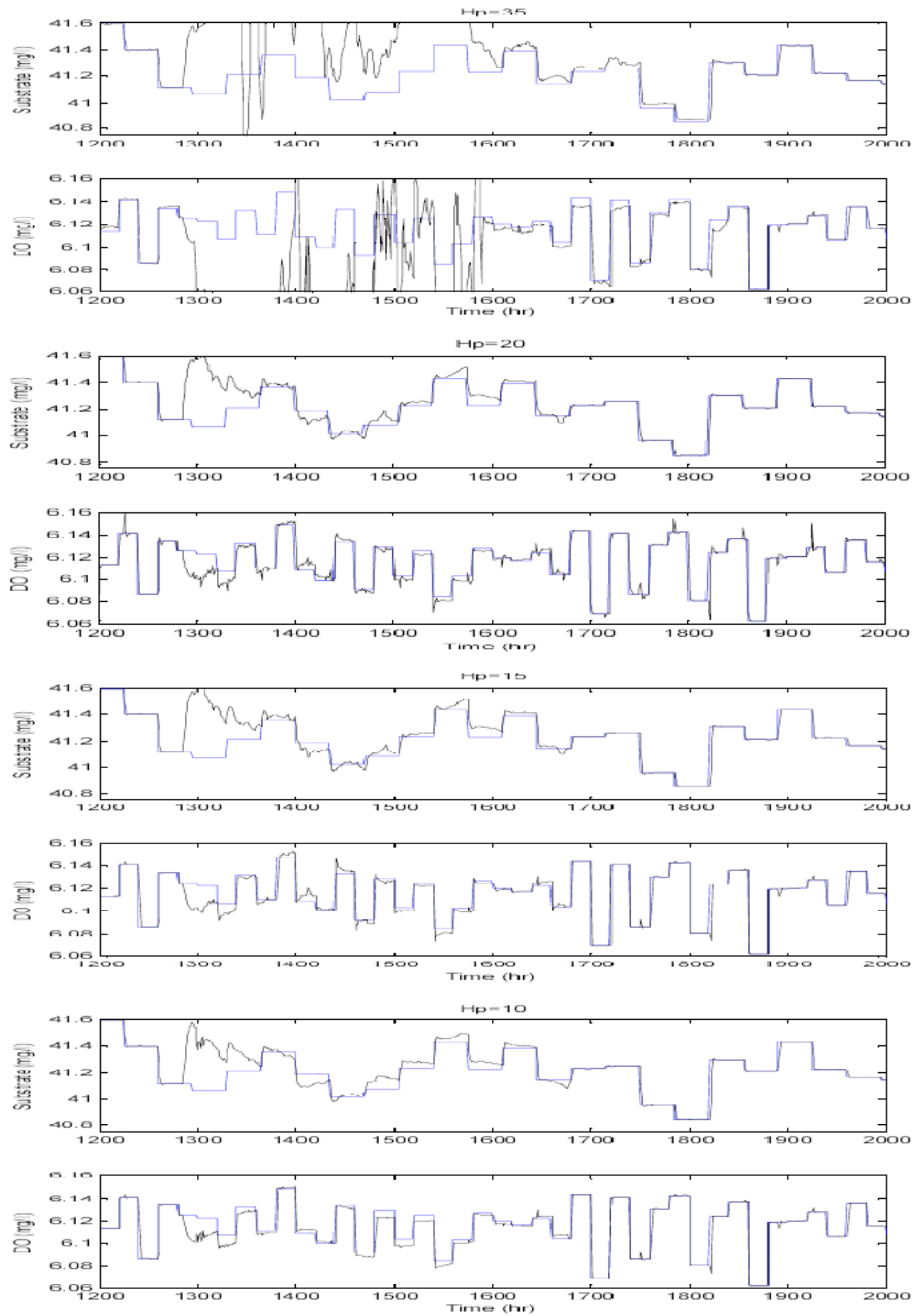

Figure 7 Performance comparison for different $H_{p}$-output response 

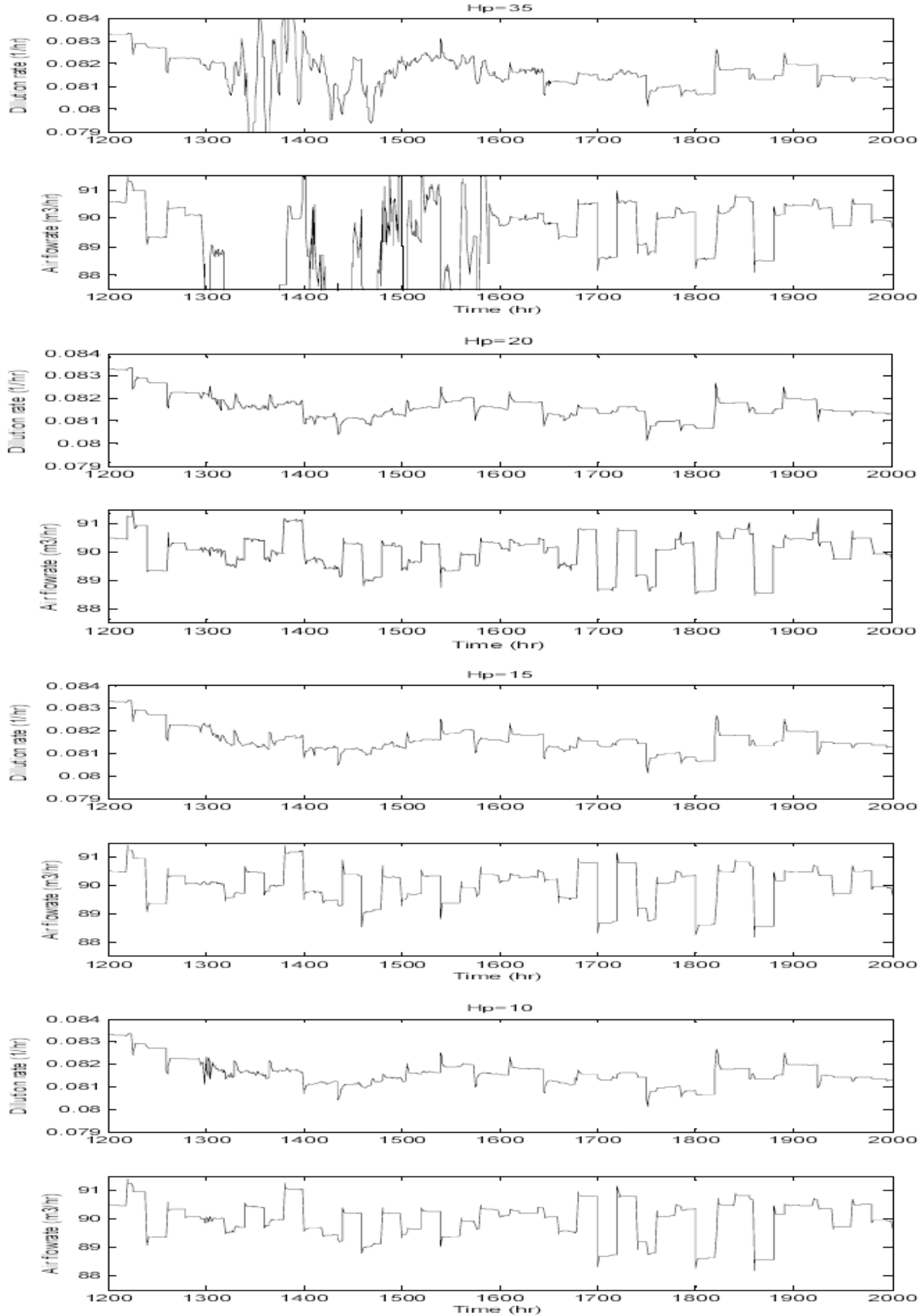

Figure 8 Performance comparison for different $H_{p}$-input response 


\subsection{Computation Time}

Tables 1-2 summarise the computation times (in sec) per sampling instant for two different methods. The computational time is recorded for different $n$ and the prediction horizon is constant at $H_{p}=20$ as shown in Table 1 . As indicated in Table 1, the difference in computation times between SVD-based strategy and QP-based strategy is more than 90 percent for $n=200$. Both methods requires more time as the identification window is increased. The difference is significant when the identification window is set to $n=900$. For different prediction horizons where $n$ is fixed at 400, the computational time has been recorded as shown in Table 2. Comparing both design methods, the computational burden associated to the QP problem is much higher. In particular for $H=35$, IAMPC-QP requires 10 times the computational effort demanded by IAMPC-SVD.

Table 1 CPU average times per sampling instant for different $n$

\begin{tabular}{ccc}
\hline$n$ & $\begin{array}{c}\text { IAMPG } \\
\text { (SVD) }\end{array}$ & $\begin{array}{c}\text { IAMPG } \\
(\mathbf{Q P})\end{array}$ \\
\hline 200 & 0.006 & 0.075 \\
400 & 0.012 & 0.08 \\
900 & 0.087 & 0.12 \\
\hline
\end{tabular}

Table 2 CPU average times per sampling instant for different $H_{p}$

\begin{tabular}{ccc}
\hline $\boldsymbol{H}_{p}$ & $\begin{array}{c}\text { IAMBPG } \\
(\text { SVD) }\end{array}$ & $\begin{array}{c}\text { IAMBPG } \\
(\mathbf{Q P})\end{array}$ \\
\hline 35 & 0.018 & 0.111 \\
20 & 0.012 & 0.102 \\
15 & 0.009 & 0.096 \\
10 & 0.006 & 0.090 \\
\hline
\end{tabular}

\subsection{CONGLUSION}

This paper presents the use of data-driven control models in an adaptive framework applied to an activated sludge wastewater treatment process. The control design uses an online subspace model identification technique, implemented in an adaptive control context along with the MPC controller. Several design parameters have been selected in the IAMPC control design. The 
control design parameters have been tested for several different values to investigate the stability and performance of the IAMPC when applied to a nonlinear system. The proposed IAMPC control technique can be applied to constrained multivariable systems.

\section{ACKNOWLEDGEMENTS}

The work has been supported financially by Malaysian Government and Universiti Teknologi Malaysia. This support is gratefully acknowledged.

\section{REFERENGES}

[1] Bartlett, R. A., L. T. Biegler, J. Backstrom and V. Gopal. 2002. Quadratic Programming Algorithms for Large-Scale Model Predictive Control. Journal of Process Control. 12(7): 775-795.

[2] Literature Survey. 2010. Adaptive Control and Signal Processing Survey (No. 17). Int. J. Adapt. Control Signal Process. 24: 337-342.

[3] Wang X., B. Huang, and T. Chen. 2007. Data Driven Predictive Control for Solid Oxide Fuel Cells. Journal of Process Control. 17: 103-114.

[4] Rao, C. V., S. J. Wright and J. B. Rawlings. 1998. Application of Interior Point Methods to Model Predictive Control. Journal of Optimization Theory and applications. 99(3): 723-757.

[5] Serón, M. M., José A. De Doná and G. C. Goodwin. 2000. Global Analytical Model Predictive Control with Input Constrains. In Proceedings of the $39^{\text {th }}$ IEEE Conference on Decision and Control.

[6] Bemporad, A., M. Morari, V. Dua and E. N. Pistikopoulus. 2002. The Explicit Linear Quadratic Regulator for Constrained Systems. Automatica. 38: 3-20.

[7] Johansen, Tor A., I. Petersen and O. Slupphaug. 2002. Explicit Suboptimal Linear Quadratic Regulation With State And Input Constraints. Automatica. 38: 1099-1111.

[8] Kouvaritakis, B., M. Cannon and J. A. Rossiter. 2002. Who Needs QP for Linear MPC Anyway? Automatica. 38: 78-814.

[9] Biegler, L. T. 1997. Advanced In Nonlinear Programming Concepts for Process Control. In proceedings of IFAC Adchem Conference. Banff, Canada.

[10] Rojas, O. J., G.C. Goodwin, M. M. Serón and A. Feuer. 2004. An SVD-based Strategy for Receding Horizon Control of Input Constrained Linear System. International Journal of Robust and Nonlinear Control. 14: 1207-1226.

[11] Dochain, D. and M. Perrier. 1993. Control Designfor Nonlinear Wastewater Treatment Processes. Water Science and Technology. 28(11-12: 283-293.

[12] Nejjari, F., A. Benhammou and B. Dahhou. 1996. Predictive Control of a Nonlinear Biological Wastewater Treatment Process. In Proc. CIM ASI 96, Casablanca.

[13] Nejjari, F., B. Dahhou, A. Benhammou and G. Roux. 1999. Non-linear Multivariable Control of an Activated Sludge Wastewater Treatment Process. International Journal of Adaptive Control and Signal Processing. 13: 347-365.

[14] De Moor, B. 1988. Mathematical Concepts And Technique For Modelling Of Static And Dynamic Systems. PhD Thesis. Dept. of Electrical Engineering, Katholieke Universiteit Leuven, Belgium.

[15] Van Overschee, P. and B. De Moor. 1996. Subspace Identification for Linear Systems: Theory Implementation Applications. Kluwer Academic Publishers.

[16] Golub, Gene H. and Charles F. Van Loan. 1996. Matrix Computation. The Johns Hopkins University Press. Baltimore, Maryland, USA. 
[17] Takács, I., G. G. Patry and D. Nolasco. 1991. A Dynamic Model of the Clarification-Thickening Process. Water Research. 25(10): 1263-1271. 